\title{
Paleopatología craneal de la necrópolis talayótica de Son Real (Mallorca)
}

\section{Cranial paleopathology in the talayotic necropolis from Son Real (Mallorca)}

\section{DANIEL TURBÓN}

Universidad de Barcelona. Facultad de Biología. Depto. Biología Evolutiva, Ecología y Ciencias Ambientales.

Sección de Zoología y Antropología Biológica

Avda. Diagonal, 643, E-08028 Barcelona

turbon@ub.edu

\section{DOMÈNEC CAMPILLO}

Universidad de Barcelona. Facultad de Biología. Depto. Biología Evolutiva, Ecología y Ciencias Ambientales. Sección de Zoología y Antropología Biológica

Avda. Diagonal, 643, E-08028 Barcelona

\section{Miguel Botella}

Universidad de Granada. Facultad de Medicina. Depto. Medicina Legal, Toxicología y Antropología Física.

Laboratorio de Antropología.

Avda. de la Investigación 11, E-18071 Granada

mbotella@ugr.es

Se estudian nueve casos inéditos de patología craneal de la necrópolis talayótica mallorquina de Son Real (Alcúdia) que datan de los siglos vir al II a.n.e. Este nuevo material se añade a los casos anteriormente documentados (Campillo, 1977; 2007). Un caso de neoplasia maligna, o quizá de histiocitosis, destaca particularmente. Por otra parte, se recogen en dos tablas todos los casos descritos de patología craneal de esta necrópolis baleárica. Pretendemos ofrecer así un panorama de conjunto, así como su discusión, que pensamos que puede ser útil a los no especialistas.

\section{PALABRAS CLAVE}

SON REAL (MALLORCA), PALEOPATOLOGÍA CRANEAL, TRAUMATISMO, INFECCIÓN, NEOPLASIA MALIGNA

We study nine unpublished cases of cranial pathology of the Majorcan Talayotic necropolis of Son Real (Alcúdia) dating from the seventh to the second centuries BC. This new material is added to the cases previously documented (Campillo 1977; 2007). A case of malignant cranial neoplasm, or perhaps histiocytosis, stands out particularly. On the other hand, all the described cases of cranial pathology of this Balearic necropolis are summarized in a table. We intend to offer a panorama of the whole and as well as its discussion that we think can be useful to non-specialists.

\section{KEYWORDS}

SON REAL (MALLORCA), CRANIAL PALEOPATHOLOGY, TRAUMATISM, INFECTION, MALIGNANT CRANIAL NEOPLASM 


\section{Introducción}

Son Real es una necrópolis talayótica mallorquina cuyos enterramientos están datados entre los siglos vir y II a.n.e. Situada al borde del mar en la bahía de Alcúdia, cerca de Can Picafort, en la finca de Santa Margalida, es conocida como el Cementiri dels Fenicis. El nombre de cultura talayótica procede de las construcciones en forma de torre que se denominan talaiots (atalaya pequeña). Son Real sería una necrópolis de finales del período talayótico y de buena parte de la época balear. El lector interesado puede conocer los aspectos de Son Real consultando Tarradell (1964), Hernández-Gasch (1997 y 1998), Tarradell y Hernández-Gasch (1998), Hernández-Gasch et al. (2005), Hernández-Gasch y Ramis (2010), Hernández-Gasch et al. (2010), Hernández-Gasch et al. (2013), Hernández-Gasch et al. (2017), Hernández-Gasch et al. (2019) y Calvo y García-Rosselló (2019).

La necrópolis de Son Real, aún recubierta de arena, estaba siendo expoliada progresivamente desde 1957, al aflorar las tumbas. La dirección de los trabajos fue encomendada a M. Tarradell (1959; 1964), bajo el patrocinio de la Fundación Bryant, que excavaba por entonces la cercana ciudad romana de Pollentia. Tarradell llevó a cabo cinco campañas durante 12 años (1957 a 1969). Hubo una intervención anterior de Enseñat, en 1955. Tarradell remitió los restos humanos de 165 individuos de Son Real en distinto estado de conservación, al catedrático Santiago Alcobé de la Facultad de Ciencias de la Universidad de Barcelona, quien encomendó el estudio antropológico a Amparo Font (1974). Esta investigadora permitió el acceso a la colección Son Real de Barcelona a D. Campillo, para su estudio paleopatológico, mientras ambos realizaban sus respectivas tesis doctorales. En 1977 Campillo publicó su estudio paleopatológico, en el que incluyó los restos craneales de Son Real de las colecciones existentes por entonces: Universidad de Barcelona; en Mallorca, la Colección Enseñat, y la del Museo de Alcúdia, más un caso depositado en el Museo de Mallorca.

Entre 1988 y 1990 se llevó a cabo un estudio de reconstrucción paleoecológica de diversas poblaciones humanas españolas, prehistóricas e históricas, de diferentes períodos y zonas geográficas. Los aquí firmantes participaron como investigadores del proyecto de investigación coordinado DGICYT PB88-0193-C03, del Programa Sectorial de Promoción General del Conocimiento del MEC (Turbón et al., 1991). A partir del registro osteológico, se examinaron más de mil doscientos individuos — trabajando coordinadamente y utilizando la misma metodología a fin de que los datos fueran comparables-, estudiándose aspectos demográficos, determinación de la dieta, marcadores de procesos anémicos y de crisis nutricionales durante el crecimiento y desarrollo, actividad física, así como una amplia gama de patologías. Algunos casos de patologías óseas registradas han permanecido inéditos.

En el presente artículo se estudian nueve casos patológicos inéditos de la necrópolis de Son Real, de la colección de la Universidad de Barcelona (desde abril de 2014 devueltos al Museo de Mallorca), estudiados por D. Campillo no en 1977, sino en 1988, como investigador del mencionado proyecto. 


\section{Material y métodos}

La mayoría de los cráneos humanos de Son Real fueron estudiados desde el punto de vista paleopatológico por Campillo (1977). En la Colección Enseñat, de Mallorca, examinó cinco casos de Son Real, tres de los cuales presentaban patologías craneales; de la Colección Son Real del Museo de Alcúdia, Campillo examinó 171 casos, encontrando 37 con señales paleopatológicas; finalmente, en el Museo de Mallorca halló un caso: el 29-1 (Campillo, 1977: 32).

Tratamos aquí 11 casos de restos craneales —incluyendo mandíbulas, nueve de ellos inéditos - de la entonces colección barcelonesa, estudiados en 1988 en el mencionado proyecto de investigación. D. Campillo los examinó, diagnosticó, fotografió y procedió a radiografiarlos oportunamente. De los 11 individuos publicamos aquí material fotográfico inédito. Dos de los casos, el 29-1 y el 43-6, ya habían sido estudiados por Campillo (1977).

Asimismo, aportamos sendas tablas de las patologías no solo del presente estudio, sino también de las descritas para el conjunto de la necrópolis de Son Real, que facilitan la visión de conjunto.

\section{Resultados}

La tabla 1 contiene el conjunto de diagnósticos de los casos inéditos de paleopatologías craneales, incluyendo mandíbulas de Son Real del presente estudio, realizados en el contexto del proyecto DGYCIT aludido. Se describen a continuación:

1. Son Real 22-2. Erosión a nivel del conducto auditivo externo derecho que parece corresponderse con una otitis (fig. 1).

2. Son Real 28-2. Neoplasia maligna, primitiva o metastásica (fig. 2). Hay un diagnóstico alternativo: histiocitosis.
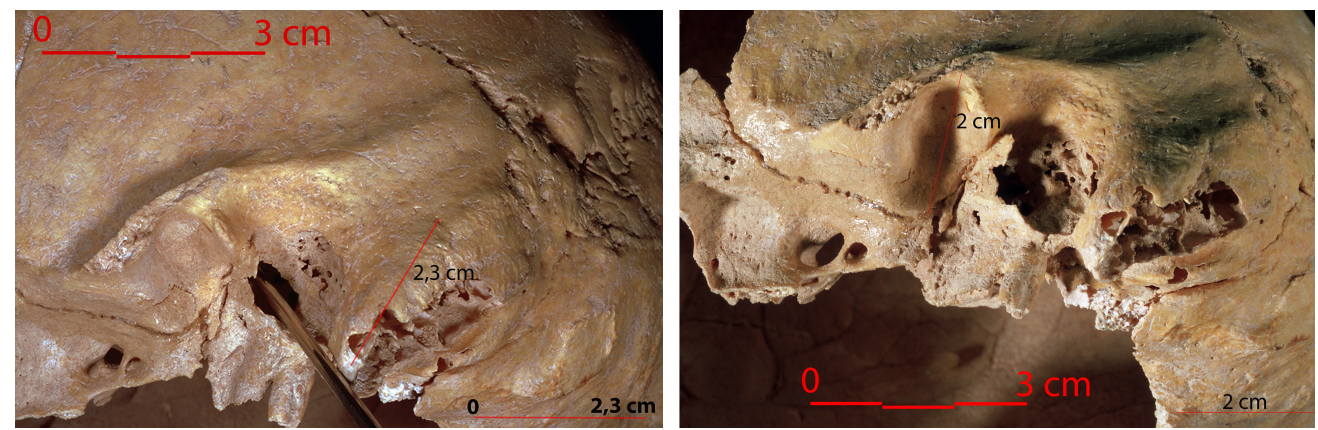

Figura 1. Son Real 22-4. Afección en el oído izquierdo. a) ¿Otitis? b) ¿Osteítis? 

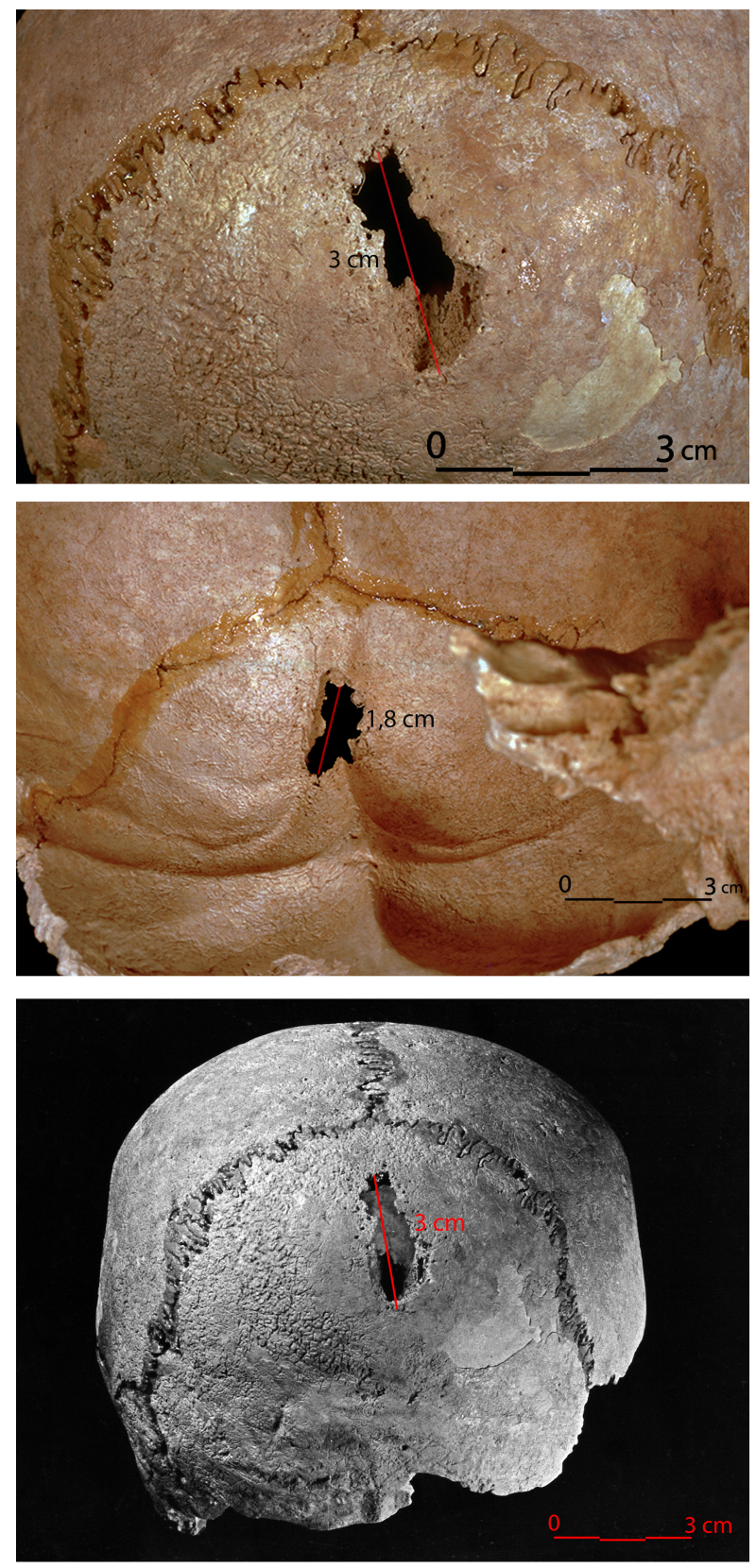

Figura 2. Son Real 28-2. Neoplasia maligna, posible histiocitosis. Escama occipital suprainíaca con pérdida ósea de contorno irregular. Alrededor del orificio mayor se observa la presencia de numerosos orificios pequeños vasculares noviformados. a) Exocraneal. b) Endocraneal. c) Visión general. 
Figura 3. Son Real 29-1. Traumatismo craneal.

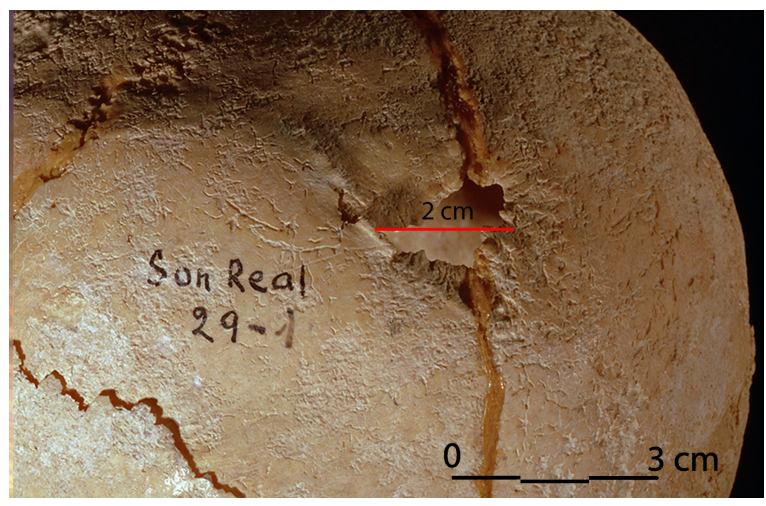

Calota craneal a la que falta el temporal derecho y la parte anterior de la escama occipital infrainíaca, que comprende también el orificio occipital y la apófisis basilar. Parece tratarse de adulto joven, ya que todas las suturas están libres, tanto en el endocráneo como en el exocráneo. En la escama occipital suprainíaca, en la línea media, se observa una pérdida de substancia ósea de contorno irregular geográfico, cuyo eje mayor en sentido sagital mide $30 \mathrm{~mm}$, siendo los transversales de $9 \mathrm{~mm}$ en la porción superior y de $13 \mathrm{~mm}$, en la inferior en la cara exocraneal. En su cara endocraneal los diámetros son menores: $18 \times 10 \mathrm{~mm}$. Alrededor del orificio, un marco de 5 a $7 \mathrm{~mm}$, se observa la presencia de numerosos pequeños orificios vasculares noviformados. En el endocráneo, la perforación afecta el surco del seno longitudinal superior, que como acostumbra a ser habitual está desplazado hacia la derecha. Macroscópicamente no se aprecia reacción ósea. En la radiografía se observa una reacción ósea condensante que afecta el contorno derecho del orificio. Por ser un individuo adulto joven, parece que la etiología más probable de esta lesión metastásica sea un osteosarcoma, un tumor de Ewing o bien, con menos probabilidad, una histiocitosis.

1. Son Real 29-1. Traumatismo craneal (fig. 3).

2. Son Real 43-6. Erosión craneal derecha de probable etiología traumática (fig. 4).

3. Son Real 72-2. Erosión a nivel de la glabela que penetra en el seno frontal, de probable origen postraumático con una sobreinfección que tal vez dio origen a una sinusitis (fig. 5).

4. Son Real 24-1 (mandíbula). Tubérculo molar supernumerario, molar supernumerario (fig. 6).

5. Son Real 32-2. Osteítis con reabsorción (fig. 7).

6. Son Real 51-1. Absceso de origen dental, quiste radicular (fig. 8).

7. Son Real 53-2 Probable persistencia del diente 84 (primer molar derecho deciduo). Diagnóstico sin completar porque no se radiografió la mandíbula (fig. 9).

8. Son Real 67-4 Persistencia del diente 85 (segundo molar derecho deciduo) (fig. 10).

9. Son Real 72-2 Artropatía degenerativa, en ambos cóndilos mandibulares, con reacción exostosante (fig. 11). 


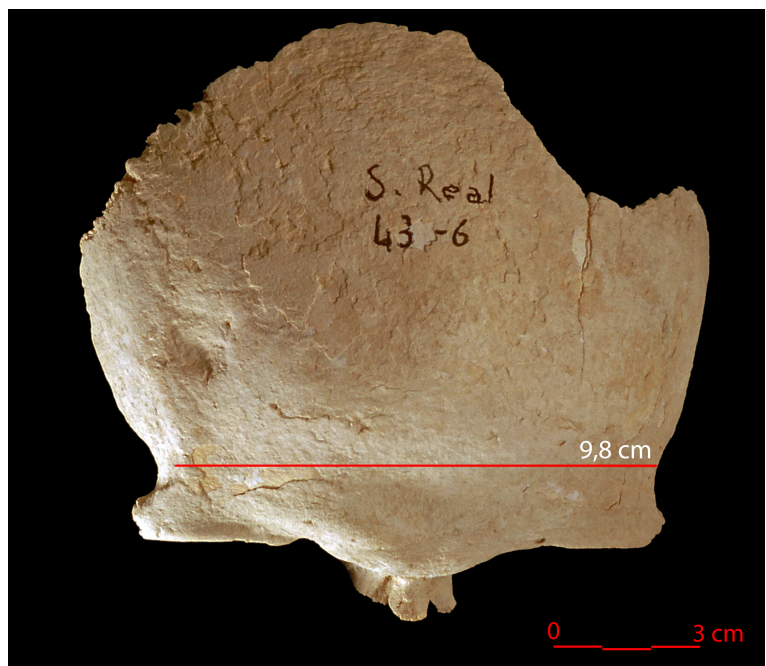

Figura 4. Son Real 43-6. Erosión craneal derecha de probable etiología traumática.

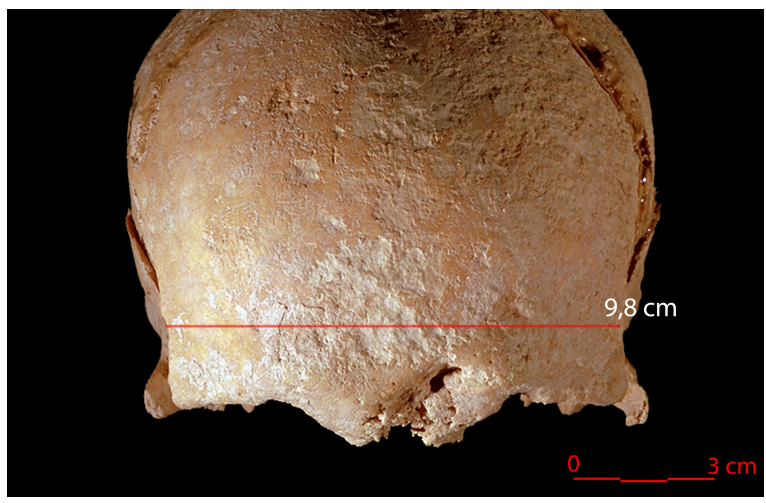

Figura 5. Son Real 72-2. Erosión a nivel de la glabela que penetra en el seno frontal, de probable origen postraumático con una sobreinfección que, tal vez, dio origen a una sinusitis.

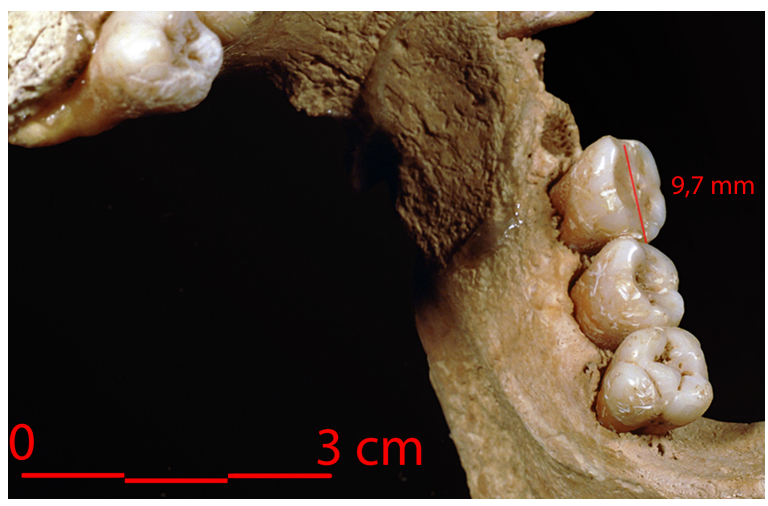

Figura 6. Son Real 24-1 (mandíbula). Tubérculo molar supernumerario, ¿diente supernumerario? 
Figura 7. Son Real 32-2. Osteítis

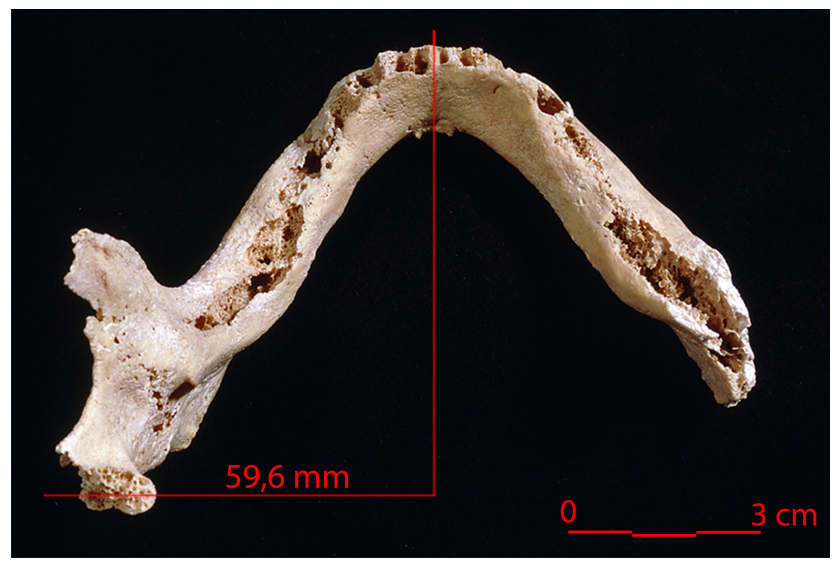

con reabsorción.

Figura 8. Son Real 51-1. Absceso de origen dental, quiste radicular.

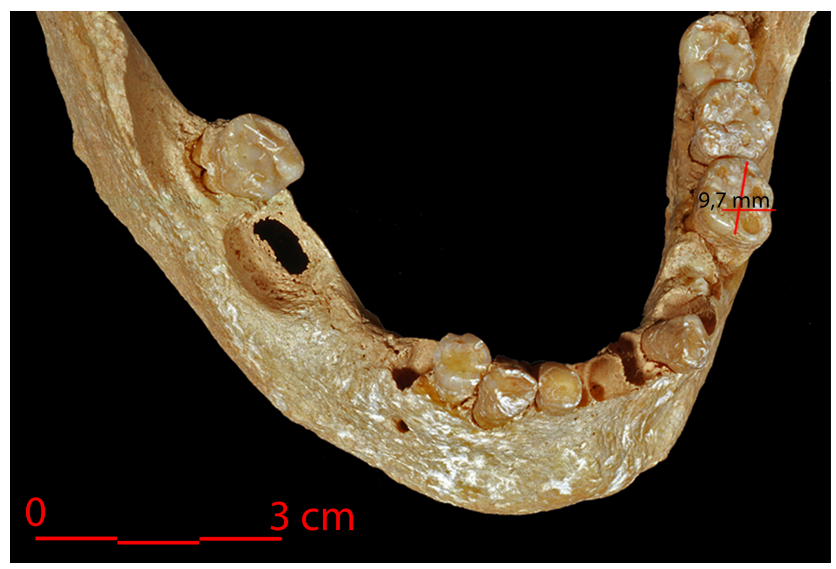

Figura 9. Son Real 53-2. Persistencia del diente 84 (primer molar derecho deciduo).

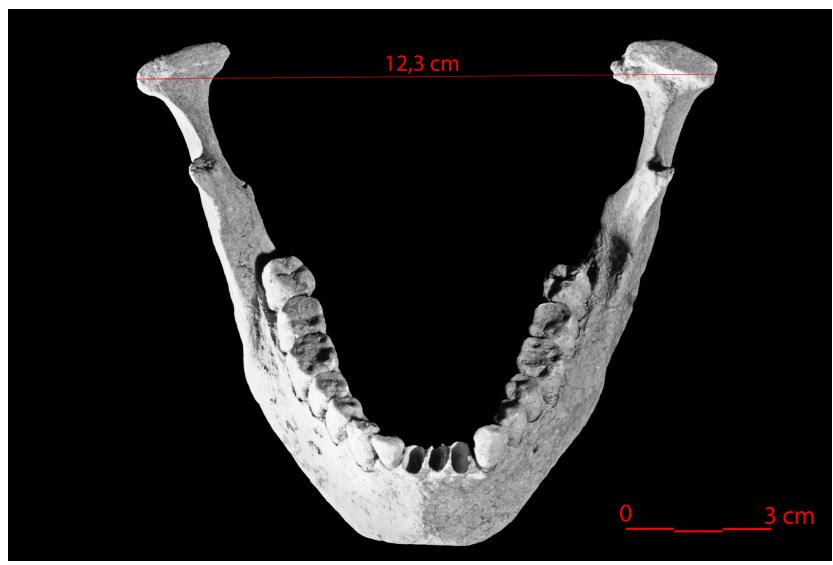




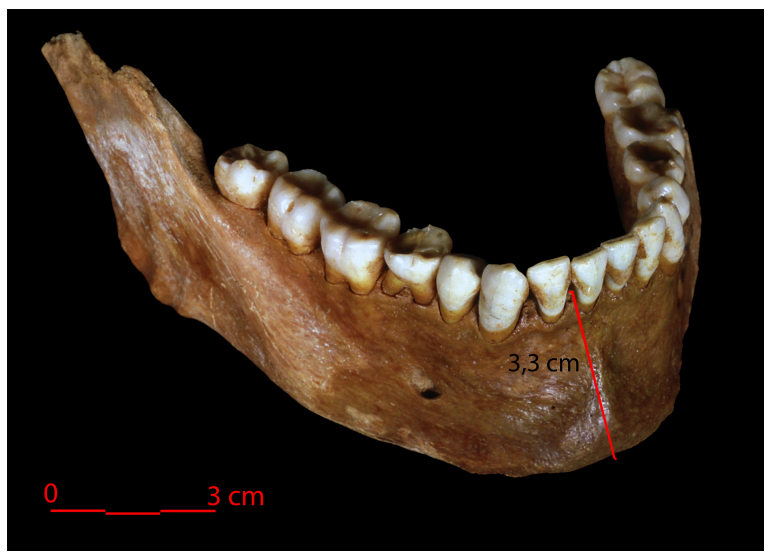

Figura 10. Son Real 67-4. Anomalía dental, persistencia del diente 85 (segundo molar derecho deciduo).

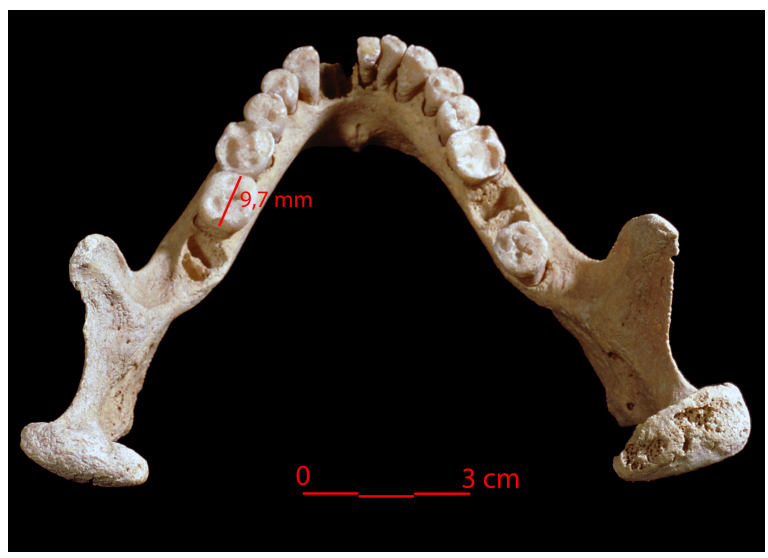

Figura11. Son Real 53-2. Artritis en ambos cóndilos con reacción exostosante.

Dos de los casos, el 29-1 y el 43-6, no son inéditos en cuanto a la descripción (Campillo 1977), aunque el primero sí lo es en lo tocante a la calidad de las ilustraciones que aportamos; del segundo no hay en Campillo (1977) ninguna fotografía; las ofrecemos en este artículo.

\section{Discusión}

Algunas de las patologías ya habían sido detectadas en otros casos de Son Real (Campillo, 1977), que resumimos en la tabla 2. Sin embargo, otros son nuevos y no descritos en la mencionada necrópolis, como por ejemplo una lesión metastásica o bien una histiocitosis, así como afecciones mandibulares. 
Las erosiones craneales y las trepanaciones son los grupos de lesiones más frecuentes en Son Real (tabla 2) entre los 175 individuos examinados. Campillo (1977) observó 25 erosiones, a las que deben sumarse las del presente trabajo, tres casos más, sin que se conozca el grupo al que pudieran asignarse. Consideramos erosiones craneales aquellas lesiones poco profundas, que afectan la tabla externa erosionando el diploe solo superficialmente, cuando esto ocurre. En todos los casos los signos de regeneración ósea son evidentes, lo que confirma que se trata de lesiones con supervivencia del individuo tras el traumatismo o erosión. No se han tomado en cuenta este tipo de lesiones en los cráneos mal conservados, sea por que pasan desapercibidas o por que se interpretan como deterioros post mortem. Campillo $(1977,231)$ las divide en ocho categorías. De los 25 casos, ocho pertenecen al grupo I y seis a los grupos II y III, respectivamente. Para el caso de marcas en los huesos, diferenciales de las mencionadas erosiones, un libro particularmente útil es el de Botella et al. (2000).

Hay descritos otros casos de tumores malignos en la literatura científica de cráneos prehistóricos (véase el capítulo VII de Campillo, 1977, con amplia documentación), entre los que destacan el del Barranc d'Algendar en Menorca y el conocido caso del cráneo 2 de la Cova Joan d'Os de Tartareu (Lleida). Son Real 28-2 presenta una lesión metastásica, situada en la escama occipital suprainíaca con pérdida ósea de contorno irregular. Alrededor del orificio mayor se observa la presencia de numerosos orificios pequeños vasculares noviformados. En cuanto a la histiocitosis, un histiocito es una célula diferenciada que tiene su origen en la médula ósea. Se ha debatido si la histiocitosis de células de Langerhans y la enfermedad de Erdheim-Chester son enfermedades inmunitarias inflamatorias o afecciones parecidas al cáncer. Recientemente, mediante la genómica se ha demostrado que algunas formas de histiocitosis generan mutaciones en los genes de los glóbulos blancos inmaduros. Esto causa un comportamiento anormal en las células. Posteriormente, el número de células anormales aumenta en varias partes del cuerpo que incluyen los huesos, la piel, los pulmones y otras áreas.

El interesante caso del individuo 29-1 ya fue ampliamente estudiado por Campillo (1977). Sin embargo, este autor lo incluyó en su informe de nuestro proyecto DGICYT añadiendo una fotografía de excelente calidad que aquí damos a conocer. Se trata de un traumatismo craneal de una mujer joven, de unos veinte años de edad, que según la autorizada opinión de Campillo $(1977,306)$ recibió un golpe tangencial de arriba abajo con un instrumento cortante, con el agresor delante, que le arrancó una lasca del hueso parietal. Hay signo evidente de reacción cicatricial y hubo supervivencia prolongada.

Respecto a las erosiones craneales, Campillo incluyó Son Real 43-6 en su informe, que presenta una erosión hallada en el lado derecho del hueso frontal. Corresponde a un adulto de unos veinticinco años de edad y de sexo masculino. La zona erosionada tiene forma circular con un diámetro de 14-15 mm y una profundidad de $3 \mathrm{~mm}$. En la radiografía se observa una condensación ósea alrededor de la erosión, lo que permite afirmar que la lesión se produjo en vida. Publicamos aquí sus fotografías en color y blanco y negro, pues en Campillo 1977 solo hay un dibujo. 
Los casos 32-2 (fig. 7) y 51-1 (fig. 8) presentan afecciones óseas del aparato masticatorio. El diagnóstico del primero es osteítis con reabsorción y el del segundo, un absceso de origen dental con quiste radicular.

Por otra parte, se aportan tres casos de anomalías dentales: un tubérculo supernumerario y dos casos en los que persiste en la edad adulta un molar de la dentición de leche (SR S/N de diagnóstico probable y SR 67-4 de diagnóstico inequívoco). SR 24-1 es una mandíbula (fig. 6) cuyo tercer molar derecho presenta una división anómala en la zona del hipocónido e hipoconúlido con exagerada expansión hacia el lado lingual, lo que probablemente sea una anomalía genética del individuo. Las cúspides dentales de los mamíferos, muy estudiadas desde la sistematización de Cope y Osborn, a comienzos del siglo pasado, se repiten sistemáticamente en cuanto a formas y cúspides en las distintas especies, lo que demuestra una marcada base genética. Sin embargo, Glasstone (1967; 1971) demostró que, en gérmenes de molar de ratón, aislados y cultivados in vitro, se dieron cambios reguladores en la expresión génica ya desde el momento inicial del desarrollo, por más que las cúspides se formaran sin apenas alteraciones, en el cultivo celular, por estar morfogenéticamente muy determinadas. Estos aspectos han experimentado un gran avance investigador en medicina regenerativa (Bansal y Jain, 2015).

Se han registrado persistencias de molares deciduos en SR 53-2 (fig. 9) y SR 67-4 (fig. 10), primero y segundo molar respectivamente, en el lado derecho mandibular de ambos casos, siendo el de SR 67-4 debido probablemente a agenesia (no erupción) del segundo premolar. Respecto a Son Real 53-2 el diagnóstico está sin completar por que no se radiografió la mandíbula, al realizarse el estudio en 1988.

Son Real es, con mucho, el yacimiento más importante del período talayótico en cuanto a trepanaciones. Se han identificado 14 cráneos trepanados de 175 individuos examinados, un $8 \%$. Esta cifra debe tomarse solamente como una aproximación, pues la acción del mar por un ligero cambio del nivel marino afectó Son Real (Pericot, 1975) y, aunque esta necrópolis se encuentra sobre un pequeño altozano, el ascenso del nivel marino fue responsable de la desaparición de un 30 \% de Son Real (Hernández-Gasch et al., 2019).

Elaborar estadísticas en este contexto resulta poco fiable y arriesgado por estar afectadas por un conjunto de sesgos. Uno es el largo tiempo de utilización de la necrópolis, cinco siglos. A pesar de que la excelente labor arqueológica de algunos investigadores haya minimizado este riesgo, desconocemos el porcentaje de incertidumbre. Otro es la probable falta de representatividad de los restos respecto al efectivo poblacional de cada siglo. Un tercero es la desaparición de restos por expolio, durante siglos o por razones tafonómicas. Finalmente, es usual en los estudios antropológicos de época prehistórica e histórica que el número de individuos registrado arqueológicamente sea mucho más elevado que el efectivo, pues no pocos son restos infantiles, fragmentados o escasos, siendo en la práctica inviable su evaluación. Advertido lo cual, hay indicios de que pudieran considerarse válidos, como mera orientación. En los casos trepanados de Son Real predomina el sexo masculino (nueve individuos) sobre el femenino (dos casos, uno de ellos de diagnóstico dudoso); hay otros dos casos de sexo indeterminable y un caso 
infantil. Si se aceptara este dato, se confirmaría la opinión extendida entre la mayoría de los autores, que destacan la rareza de esta práctica en la mujer y su excepcionalidad en el niño.

En lo que se refiere a las técnicas, en Son Real se aplicaron las tres formas clásicas: barrenado, abrasión e incisa, si bien esta última solo se da en un caso póstumo, mientras que la de abrasión está asociada a los casos seguidos de supervivencia. La técnica de barrenado se observa tanto en los casos quirúrgicos como en los post mortem, aunque los orificios cónicos de diámetro amplio solo aparecen en los seguidos de supervivencia. Ello puede deberse a una ampliación del orificio por necrosis ósea con reabsorción del borde seguida de cicatrización, dando origen a orificios irregulares (S.R. II y S.R. 9-67 I), mientras que la segunda sería debida al empleo de una «broca» con punta de ángulo abierto o procediendo al ensanchamiento del orificio mediante el empleo sucesivo de distintas «brocas», cada vez mayores (Campillo, 2007).

Con relación al número de perforaciones, en nueve casos era única y en cinco, múltiples, debiéndose destacar que en todos los casos con supervivencia la perforación fue única, excepto en el individuo 19-1, que muestra dos orificios. Existe un discreto predominio en favor de las trepanaciones in vivo con respecto a las póstumas en proporción de 8 a 6. En un solo caso se aprecia una presunta alteración patológica, consistente en impresiones digitales, sugestivas de una hipertensión endocraneal, aunque por tratarse de un niño este diagnóstico resulta incierto. Además, la trepanación fue póstuma pudiendo no tener intencionalidad curativa, sino la obtención de un amuleto o recuerdo del difunto. Solo en dos casos se observaron signos inflamatorios y, en uno de ellos, se pudo constatar la presencia de una reacción estriada cicatricial (Campillo, 1977).

Las trepanaciones baleáricas parecen pertenecer a un período posterior —que en Son Real va de los siglos VII a II a.n.e.- al de los restantes yacimientos de Mallorca y de Menorca; poco debieron diferir en el tiempo. Así pues, dado que en la Península Ibérica se implantó la incineración de cadáveres, se ignora si se dejó de trepanar, mientras que al menos en Son Real perduró durante la segunda Edad del Hierro (La Tène), lo que refuerza la idea de la estrecha relación entre las Baleares y las talasocracias mediterráneas.

\section{Conclusiones}

De las lesiones paleopatológicas aportadas en el presente artículo, algunas ya habían sido descritas por D. Campillo (1977); otras afecciones son inéditas y no registradas en Son Real hasta hoy. Por ejemplo, una lesión metastásica que también pudiera ser una histiocitosis. Además, hay un caso de otitis con erosión del conducto auditivo externo; un traumatismo craneal; diversas erosiones craneales, una de ellas por traumatismo, otra con sobreinfección postraumática, causando una sinusitis; así como varias afecciones mandibulares, tales como un caso de artropatía degenerativa en ambos cóndilos mandibulares con reacción 
Tabla 1. Patologías craneales de la necrópolis de Son Real estudiadas por D. Campillo en 1988. Clasificación descrita por Campillo (presente estudio)

\begin{tabular}{clcl}
\hline Cráneos & Patologías & Cráneos & Mandíbula \\
\hline $22-2$ & Otitis: Erosión del conducto auditivo derecho externo & $24-1$ & $\begin{array}{c}\text { Dientes supernumerarios: Tubérculo molar } \\
\text { supernumerario }\end{array}$ \\
\hline $28-2$ & $\begin{array}{c}\text { 0steosarcomas: Escama occipital suprainíaca con pérdida } \\
\text { ósea de contorno irregular. Alrededor del orificio se } \\
\text { observan numerosos orificios pequeños vasculares } \\
\text { noviformados }\end{array}$ & $53-2$ & $\begin{array}{c}\text { Artritis: Artritis en cóndilos mandibulares con } \\
\text { reacción exostosante }\end{array}$ \\
\hline 29-1 & Traumatismos: Traumatismo craneal & $51-1$ & Quiste radicular: Absceso de origen dental \\
\hline 43-6 & $\begin{array}{c}\text { Traumatismos: Erosión craneal por un traumatismo } \\
\text { 72-2 }\end{array}$ & Postraumatismos: Erosión a nivel de la glabela hasta el \\
& $\begin{array}{l}\text { seno frontal. Postraumatismo con sobreinfección } \\
\text { posiblemente dando lugar a una sinusitis }\end{array}$ & SN & $\begin{array}{c}\text { Persistencia de dientes: Probable } \\
\text { persistencia del diente 84 }\end{array}$ \\
\hline
\end{tabular}

Tabla 2. Frecuencia de lesiones registradas en Son Real, por Campillo (1977). Código CE: Colección Enseñat

\begin{tabular}{|c|c|c|}
\hline \multicolumn{2}{|l|}{ Paleopatologías } & Individuos \\
\hline \multicolumn{2}{|l|}{ Trepanaciones } & $\begin{array}{l}\text { I CE, II CE, V CE, 2-2, 9-67, 19-1, 22-3, 36-4, 39-1, 43-4, 46-1, 53-3, } \\
65-4,74-5,13-3,13-4\end{array}$ \\
\hline \multicolumn{2}{|c|}{ Lesiones maxilares secundarias a procesos dentarios } & $46-1$ \\
\hline \multicolumn{2}{|c|}{ Malformaciones craneales } & $3-1$ \\
\hline \multicolumn{2}{|l|}{ Osteomas } & $2-1,22-4,47-1,54-2,1966-2$ \\
\hline \multirow[t]{4}{*}{ Erosiones craneales } & Grupo I & $2-1,3-1,22-3,26-4,36-1,36-4,43-6,54-2$ \\
\hline & Grupo II & Son Real CE, 2-67(9), 13-1, 42-2, 13-3, 36-3 \\
\hline & Grupo III & Son Real CE, 2-67 (9), 13-1, 13-3, 36-3, 42-2 \\
\hline & Grupo V-VIII & $\begin{array}{l}\text { V: } 13-2 \\
\text { VI: } 1-3 \\
\text { VII: } 6-6 \\
\text { VIII: Son Real CE, 13-4 }\end{array}$ \\
\hline \multicolumn{2}{|c|}{ Traumatismos craneales } & $2-67(4), 29-1,69-1,32-1,1-2$ \\
\hline
\end{tabular}

exostosante; un quiste radicular; osteítis con reabsorción, y variantes poco frecuentes en los dientes (tabla 1$)$.

Comparadas estas lesiones y variantes dentales poco frecuentes (tabla 1) con el conjunto general de la muestra craneal de Son Real (Campillo, 1977) (tabla 2), destaca la frecuencia de trepanaciones y de erosiones craneales, respectivamente, siendo las primeras las paleopatologías más numerosas de los cráneos de Son Real. 
Esta necrópolis es el más importante conjunto de enterramientos, por el número de tumbas y por el $8 \%$ de trepanaciones registradas en el Mediterráneo occidental. Dicho porcentaje es el más alto conocido para el Occidente europeo de esa época, hasta ahora descrito. Sin embargo, debe tenerse en cuenta que distintos factores pueden haber sesgado la muestra osteológica, por lo que esta cifra solo tiene un valor orientativo.

\section{Agradecimientos}

Los autores agradecen a Mireya Alcina y a Alina Lucea su colaboración puntual en la elaboración de algunos apartados del presente artículo; igualmente agradecen a dos evaluadores anónimos las modificaciones que lo han mejorado puntualmente.

\section{Bibliografía}

BANSAL, R. y JAIN, A., 2015, Current overview on dental stem cells applications in regenerative dentistry, Journal of Natural Science, Biology and Medicine 6(1), 29-34.

BOTELLA, M., ALEMÁN, I. y JIMÉNEZ, S., 2000, Los huesos humanos. Manipulación y alteraciones, Ediciones Bellaterra, Barcelona.

CAMPILLO, D., 1977, Paleopatología de cráneo en Cataluña, Valencia y Baleares, Editorial MontblancMartín, Barcelona.

CAMPILLO, D., 2001, Introducción a la Paleopatología, Ediciones Bellaterra, Barcelona.

CAMPILLO, D., 2007, La trepanación prehistórica, Ediciones Bellaterra, Barcelona.

FONT, A., 1974, Estudio de los restos humanos procedentes de la necrópolis de Son Real, Alcudia, Mallorca, Ediciones de la Universidad de Barcelona.

GLASSTONE, S., 1967, Morphodifferentation of Theeth in Embrionic Segments in Tissue Culture, Journal of Dental Research 46(3), 611-614.
GLASSTONE, S., 1971, Differentation of the mouse embryonic mandible and squamomandibular joint in organ culture, Archives of Oral Biology 16(7), 723-728.

HERNÁNDEZ-GASCH, J., 1997, Las necrópolis de la edad del hierro de Son Real y S'Illa des Porros (Santa Margalida, Mallorca). Estudio arqueológico y análisis social, Universidad de Barcelona (tesis doctoral inédita).

HERNÁNDEZ-GASCH, J., 1998, Son Real. Necrópolis talayótica de la edad del hierro. II: Estudio arqueológico y análisis social, Edicions de la Universitat de Barcelona, Barcelona.

HERNÁNDEZ-GASCH J., SANMARTí, J., CASTRILLO, M., ALESÁN, A., ALFONSO, J., ÁLVAREZ, R., TARRADELL, N. y MALGOSA, A., 2005, Son Real revisitat: noves campanyes d'excavació a la necròpolis talaiòtica de Son Real (illa de Mallorca, 1998-2002), Mayurqa 30, 379-420.

HERNÁNDEZ-GASCH, J. y RAMIS BERNAD, D., 2010, Economia funerària de l'edat del ferro de les Illes Balears. L'ús diacrònic del sacrifici de bòvids en el santuari i les necrópolis de l'àrea de Son Real (Mallorca), Saguntum 42, 71-86. 
HERNÁNDEZ-GASCH, J., RAMIS BERNAD, D., MUNAR GRIMALT, M. y BURGAYA MARTÍNEZ, B., 2010, Informe final de la Necròpolis de Son Real (Cementiri de la punta dels Fenicis), Santa Margalida, Mallorca, Codi del Museu de Mallorca: DA08/07, del 5 al 23 de maig de 2008, MPC08, Memòria del Patrimoni Cultural. Intervencions autoritzades pel Consell de Mallorca, CD, Palma.

HERNÁNDEZ-GASCH, J., RAMIS BERNAD, D., MUNAR GRIMALT, M. y BURGAYA MARTÍNEZ, B., 2013, Memòria de la Necròpolis de Son Real (Cementiri de la punta dels Fenicis), Santa Margalida, Mallorca, Codi del Museu de Mallorca: DA10/12, del 4 al 7 d'octubre de 2010, MPC10, Memòria del Patrimoni Cultural. Intervencions autoritzades pel Consell de Mallorca, CD, Palma. HERNÁNDEZ-GASCH, J., CARDONA, F., BURGAYA, B. y MUNAR, M., 2017, Estructures inèdites al sector nord de la Necròpolis de Son Real, solucions de preservació del conjunt monumental i amenaces, en M. ANGLADA FONTESTAD, A. MARTÍNEZ ORTEGA Y M. RIERA RULLAN (eds.), VII Jornades d'Arqueologia de les Illes Balears, Museu de Menorca, Maó, 30 de setembre i 1 i 2 d'octubre de 2016, 85-90.

HERNÁNDEZ-GASH, J., BURGAYA, B., MUNAR, M., CARDONA, F., VICENS, A., VALENZUELA, L., VALENZUELA, S. y SERVERA, G., 2019,
Memòria científica de la Intervenció Arqueològica a la necròpolis de Son Real (Cementiri dels Fenicis), Santa Margalida, Mallorca. Anys 2012-2017, Programa de recerca plurianual 2013-2017. MPC16-17, Memòria del Patrimoni Cultural. Intervencions autoritzades pel Consell de Mallorca, CD, Palma. PERICOT, L., 1975, Las islas Baleares en los tiempos prehistóricos, Destino Ediciones, Barcelona.

TARRADELL, M., 1964, La necrópolis de Son Real y l'illa dels Porros. Mallorca, Excavaciones Arqueológicas en España, 24, Ministerio de Educación Nacional, Dirección General de Bellas Artes, Madrid.

TARRADELL, M. y WOODS, D. E., 1959, The Cementery of Son Real, Mallorca, Archaeology 12 (3), 194-202.

TARRADELL, M. y HERNÁNDEZ-GASCH, J., 1998, Son Real. Necrópolis talayótica de la Edad del Hierro. 1: Catálogo e inventarios, Universitat de Barcelona, Barcelona.

TURBÓN, D., BOTELLA, M., CAMPILLO, D., HERNÁNDEZ, M., JIMÉNEZ-BROBEIL, S., PÉREZPÉREZ, A., PONS, J., SOUICH DU, P. y TRANCHO, G., 1991, Efectos de la presión ambiental en poblaciones humanas, en M. BOTELLA, S. JIMÉNEZ BROBEIL, L. RUIZ y P. DU SOUICH (eds.), Nuevas Perspectivas en Antropología, Granada, Universidad de Granada, 1029-1035. 